\title{
An Empirical Model for Salinity Intrusion in
}

\section{Alluvial Estuaries}

\author{
Javad Parsa $^{1}$ and Amir Etemad-Shahidi ${ }^{2}$
}

${ }^{1}$ Department of Civil Engineering, Shahr-e-Ghods Branch, Islamic Azad University, Tehran, P.O. Box 16756-163, IRAN.Email: jparsa@iust.ac.ir

${ }^{2}$ School of Civil Engineering, Iran University of Science and Technology, Tehran, P.O. Box 16756-163, IRAN.Email: etemad@iust.ac.ir

\begin{abstract}
The main parameters that affect the salinity intrusion in estuaries are their geometric, hydrologic and hydrodynamic characteristics. The recognition of effective parameters and understanding their roles in the salinity intrusion are required for estuarine water management. In this study, the governing equations of the salinity intrusion processes were scaled to derive the effective dimensionless parameters. Then, a previously verified model, CE-QUAL-W2, was utilized as a virtual laboratory to investigate the effects of different governing parameters on the salinity intrusion. Analysis of the results showed that logarithmic functions can be used to describe the effect of dimensionless parameters obtained by scaling of governing equations. Finally, a formula was suggested to predict the salinity intrusion length based on geometrical and hydrodynamic characteristics of alluvial estuaries.
\end{abstract}

Keywords: alluvial estuaries, empirical model, numerical simulation, salinity intrusion, scaling, tidal range.

\section{Introduction}

Estuaries are coastal water bodies that act as a transition between river and sea. Water resources in coastal areas are used for drinking, agricultural and industrial purposes. Construction of dams and other water control structures in the upstream reach of rivers decreases the flow rate into the estuaries. In addition, salinity intrusion decreases the quality of estuarine water which becomes 
more severe during high tides. Hence, estuaries have been the subject of intense investigations during past decades (e.g. Etemad-Shahidi and Imberger 2002; Kapsimalis et al. 2004). The salinity distribution and salinity intrusion length may be considered as major environmental factors affecting the existence and distribution of organisms in estuaries (Jassby et al. 1995; Attrill 2002). The estuarine salinity structure is a result of the interplay between morphology and topography of an estuary, tidal range at the mouth, salinity difference between sea and river water and riverine discharge. Combinations of the above factors determine the mixing mechanism in an estuary and the salinity intrusion process (Dyer 1997).

Although the various morphological and physical parameters influencing the salinity intrusion process such as channel geometry, tidal variation and riverine discharge are described independently, it is important to realize that they interact in a complex way. Many estuarine managers and scientists are concerned about the lack of complete understanding of how these interactions occur. Hence, several attempts have been made to study these interactions and predict the salinity intrusion length (e.g. Rigter 1973; Savenije 1993; Parsa et al. 2007; Parsa and Etemad-Shahidi 2009; Zhang et al. 2011). Different alternatives such as field observations, analytical solutions, physical, empirical and numerical modeling have been used to study the salinity structure and to predict the salinity intrusion length. Field observations and physical models are very expensive and time-consuming. Analytical solutions, due to the simplifications made, can be used mostly for simple situations. Numerical models are also extensively used to simulate the hydrodynamics and salinity intrusion in estuaries and coastal water bodies (e.g. Stamou et al. 2007; Zahed et al. 2008; Liu et al. 2008). Despite the considerable flexibilities and capabilities of numerical models, they need extensive data for calibration and verification.

The advantages of the empirical models are their simple form, lack of need to extensive data and simple parameters for model set up. Therefore, they can be considered as a valuable alternative to assess the salinity intrusion length in estuaries. Predictive models mostly have an empirical component and are either inaccurate or limited to special conditions (Savenije 1993). Some of them, such as that of Sanmuganathan and Abernethy (1975, 1979), can only be used after determining the values of calibration coefficients from field measurements. Another set of the empirical models, which can be 
used without calibration, have been presented by other investigators. The methods of Van der Burgh (1972), Rigter (1973), Fischer (1974) and Van Os and Abraham (1990) only apply to prismatic estuaries with constant cross-section. The predictive model of Savenije (1986, 1993) applies to estuaries with exponentially varying cross-section and, as a result, is more accurate for the prediction of the salinity intrusion in alluvial estuaries. This model is based on the analytical solution of the steady state advectiondiffusion equation at high water slack (HWS).

This paper reports on the influences of effective parameters on the salinity intrusion and presents a formula to predict the salinity intrusion length using scaling arguments and numerical modeling. Unlike most of the previous empirical studies which utilize an analytical solution of the advection-diffusion equation, a scaling approach is used for alluvial estuaries here.

\subsection{Background}

Empirical models are easy-to-use tools for predicting the salinity intrusion length as a function of directly measurable variables such as bathymetry, riverine discharge and tidal conditions. Most of these models are based on experimental data and assume a constant cross-section for an estuary. These models are briefly presented in Table 1 (see also Savenije 2005). In this table $\mathrm{L}^{\mathrm{LWS}}, \mathrm{L}^{\mathrm{TA}}$ and $\mathrm{L}^{\mathrm{HWS}}$ are the salinity intrusion lengths at low water slack (LWS), tidally-averaged (TA) and high water slack (HWS), respectively. $h_{\circ}$ is the tidal average depth at the estuary mouth; $f$ is the Darcy-Weisbach`s roughness, $\mathrm{K}$ is Van der Burgh coefficient, $a$ is the cross-sectional area convergence length, $\beta$ is dispersion reduction rate and $\mathrm{N}$ is Canter Cremers' number defined as the ratio of the volume of river water coming down the estuary mouth during a tidal cycle and the flood volume entering the estuary over the same tidal cycle:

$$
\mathrm{N}=\frac{\mathrm{QT}}{\mathrm{P}_{\mathrm{t}}}=\frac{-\mathrm{QT}}{\mathrm{A}_{\circ} \mathrm{E}_{\circ}}=\frac{\pi}{1.08} \frac{-\mathrm{Q}}{\mathrm{A}_{\circ} \mathrm{v}_{\circ}}=\frac{\pi}{1.08} \frac{-\mathrm{u}_{\circ}}{\mathrm{v}_{\circ}}
$$

where, $\mathrm{Q}$ is the riverine discharge, $\mathrm{u}_{\circ}$ is the riverine water velocity at the estuary mouth, $\mathrm{v}_{\circ}$ is the tidal velocity amplitude at the estuary mouth, $\mathrm{A}_{\circ}$ is the cross-sectional area at the estuary mouth, $\mathrm{P}_{\mathrm{t}}$ is the tidal prism, $\mathrm{T}$ is the tidal period and $\mathrm{E}_{\circ}=1.08 \frac{\mathrm{V}_{\circ} \mathrm{T}}{\pi}$ is tidal excursion defined as 
the net horizontal distance over which a water particle moves during a tidal cycle of flood and ebb (Savenije 1993).

The densimetric tidal Froude number $F_{d}$ is defined as:

$$
F_{d}=\frac{\rho v_{\circ}^{2}}{\Delta \rho_{\circ} g h_{\circ}}=\frac{\rho}{\Delta \rho_{\circ}} F
$$

where $F=\frac{v_{\circ}^{2}}{g h}$ is the tidal Froude number, $\rho$ is the mean density of estuarine water, $\Delta \rho \circ$ is the density difference between sea and riverine water and $g$ is the gravity acceleration.

All the above mentioned empirical models, except that of Savenije (1993), have been developed for estuaries with constant geometry. Savenije (1993) found that the longitudinal variation of cross-sectional area and width in the alluvial estuaries can be expressed by the following exponential functions:

$$
\begin{aligned}
& A=A_{\circ} \exp \left(-\frac{x}{a}\right) \\
& B=B_{\circ} \exp \left(-\frac{x}{b}\right)
\end{aligned}
$$

where, $\mathrm{A}$ and $\mathrm{B}$ are the cross-sectional area and the width of estuary at a distance $\mathrm{x}$ from the mouth, respectively. $\mathrm{B}_{\circ}$ is the width at the mouth and $\mathrm{b}$ is the width convergence length. This assumption was based on the field observations of 17 estuaries worldwide and is valid for the alluvial estuaries (Savenije 2005; Nguyen and Savenije 2006; Graas and Savenije 2008).

Savenije (1993) found that convergence lengths for both cross-sectional area and width are the same in most of these estuaries. The proposed relationships for the Van der Burgh coefficient, K , and the dispersion reduction rate are given in Nguyen and Savenije (2006).

The joint solution of the salt balance equation with Van der Burgh's (1972) relationship for the dispersion yielded an equation of the type:

$$
\frac{\mathrm{L}^{\mathrm{HWS}}}{\mathrm{a}}=\ln \left(1+\frac{1}{\beta}\right)
$$


where $\mathrm{L}^{\mathrm{HWS}}$ is the salt intrusion length and $\beta$ is a dimensionless number reflecting the effects of river discharge, tide and estuary shape (see Table 1). This equation implicitly accounts for the exponential shape of the estuary and the x-dependency of the effective dispersion.

\section{The present approach}

Dimensional analysis can be used to determine the effective dimensionless parameters in salinity intrusion. Scaling used in this study is similar to the scaling of Rigter (1973) to derive a functional relationship for the length of salinity intrusion. In the present scaling, it is assumed that the salinity in the vertical direction is approximately constant along the entire estuary. Following Parsa and Etemad-Shahidi (2009), the governing equations for tidal movement and mass balance are:

$\mathrm{B} \frac{\partial \mathrm{h}}{\partial \mathrm{t}}+\frac{\partial \mathrm{Au}}{\partial \mathrm{x}}=0$

$\frac{\partial u}{\partial t}+u \frac{\partial u}{\partial x}+g \frac{\partial h}{\partial x}+\frac{g}{C^{2}} \frac{u|u|}{h}+g \frac{h}{2 \rho} \frac{\partial \rho}{\partial x}=0$

$\frac{\partial \rho}{\partial t}+u_{t} \frac{\partial \rho}{\partial x}=0$

with these boundary conditions:

$$
\begin{aligned}
& \mathrm{h}=\mathrm{h}_{\circ}+\frac{\mathrm{H}_{\circ}}{2} \sin \left(\frac{2 \pi \mathrm{t}}{\mathrm{T}}\right) \quad \text { at } \quad \mathrm{x}=0 \\
& \mathrm{uh}=-\mathrm{q}_{\mathrm{r}} \quad \text { at } \quad \mathrm{x}=\mathrm{L} \\
& \rho=\rho_{\circ} \quad \text { at } \quad \mathrm{x}=0
\end{aligned}
$$

where $\mathrm{u}$ is cross-sectional mean velocity, $\mathrm{u}_{\mathrm{t}}$ is cross-sectional mean tidal velocity, $\mathrm{q}_{\mathrm{r}}$ is riverine discharge per unit width, $\mathrm{C}$ is Chezy coefficient, $\mathrm{H}_{\circ}$ is tidal range, $\mathrm{L}$ is estuary length, $\mathrm{x}$ is horizontal distance from the mouth and $\mathrm{t}$ is time. In the salt intrusion zone the tidal velocity, $\mathrm{u}_{\mathrm{t}}$, is almost equal to the mean velocity, $\mathrm{u}$. 
The following non-dimensional variables can be introduced:

$$
\begin{aligned}
& v=\frac{u}{\sqrt{g h_{\circ}}} \\
& \eta=\frac{h}{h_{\circ}} \\
& \gamma=\frac{B}{B_{\circ}} \\
& \Gamma=\frac{\rho}{\Delta \rho} \\
& \xi=\frac{x}{a} \\
& \tau=\frac{t}{T}
\end{aligned}
$$

Resonance length can be defined as:

$$
\mathrm{L}_{\mathrm{R}}=\frac{1}{4} \mathrm{~T} \sqrt{\mathrm{gh}_{\circ}}
$$

Introducing Eqs. (12)-(18) into Eqs. (6)-(11) leads to the following equations:

$$
\begin{aligned}
& \gamma \frac{\mathrm{a}}{4 \mathrm{~L}_{\mathrm{R}}} \frac{\partial \eta}{\partial \tau}+\frac{\partial(\gamma \eta v)}{\partial \xi}=0 \\
& \frac{\mathrm{a}}{4 \mathrm{~L}_{\mathrm{R}}} \frac{\partial v}{\partial \tau}+v \frac{\partial v}{\partial \xi}+\frac{\partial \eta}{\partial \xi}+\varepsilon \frac{\mathrm{a}}{\mathrm{h}_{\circ}} \frac{v|\mathrm{v}|}{\eta}+\frac{\eta}{2 \Gamma} \frac{\partial \Gamma}{\partial \xi}=0 \\
& \frac{a}{4 L_{R}} \frac{\partial \Gamma}{\partial \tau}+v \frac{\partial \Gamma}{\partial \xi}=0
\end{aligned}
$$

with the following boundary conditions:

$$
\eta=1+\frac{\mathrm{H}_{\circ}}{2 \mathrm{~h}_{\circ}} \sin (2 \pi \tau) \quad \text { at } \quad \xi=0
$$




$$
\begin{aligned}
& v \eta=-\frac{\mathrm{q}_{\mathrm{r}}}{\mathrm{h}_{\circ} \sqrt{\mathrm{gh}}} \quad \text { at } \quad \xi=\frac{\mathrm{L}}{\mathrm{a}} \\
& \Gamma=\Gamma_{\circ} \quad \text { at } \quad \xi=0
\end{aligned}
$$

Therefore, solutions for $\eta, v$ and $\Gamma$ will be:

$$
\begin{aligned}
& \eta=\frac{\mathrm{h}}{\mathrm{h}_{\circ}}=\mathrm{f}_{1}\left(\xi, \tau ; \gamma, \frac{\mathrm{L}_{\mathrm{R}}}{\mathrm{a}}, \frac{\mathrm{h}_{\circ}}{\mathrm{a}}, \frac{\mathrm{g}}{\mathrm{C}^{2}}, \frac{\mathrm{H}_{\circ}}{\mathrm{h}_{\circ}}, \frac{\mathrm{q}_{\mathrm{r}}}{\mathrm{h}_{\circ} \sqrt{\mathrm{gh}}}, \Gamma_{\circ}, \frac{\mathrm{L}}{\mathrm{a}}\right) \\
& \mathrm{v}=\frac{\mathrm{u}}{\sqrt{\mathrm{gh}}}=\mathrm{f}_{2}\left(\xi, \tau ; \gamma, \frac{\mathrm{L}_{\mathrm{R}}}{\mathrm{a}}, \frac{\mathrm{h}_{\circ}}{\mathrm{a}}, \frac{\mathrm{g}}{\mathrm{C}^{2}}, \frac{\mathrm{H}_{\circ}}{\mathrm{h}_{\circ}}, \frac{\mathrm{q}_{\mathrm{r}}}{\mathrm{h}_{\circ} \sqrt{\mathrm{gh}}}, \Gamma_{\circ}, \frac{\mathrm{L}}{\mathrm{a}}\right) \\
& \Gamma=\frac{\rho}{\Delta \rho}=\mathrm{f}_{3}\left(\xi, \tau ; \gamma, \frac{\mathrm{L}_{\mathrm{R}}}{\mathrm{a}}, \frac{\mathrm{h}_{\circ}}{\mathrm{a}}, \frac{\mathrm{g}}{\mathrm{C}^{2}}, \frac{\mathrm{H}_{\circ}}{\mathrm{h}_{\circ}}, \frac{\mathrm{q}_{\mathrm{r}}}{\mathrm{h}_{\circ} \sqrt{\mathrm{gh}}}, \Gamma_{\circ}, \frac{\mathrm{L}}{\mathrm{a}}\right)
\end{aligned}
$$

At HWS the above equation can be rewritten as:

$$
\Gamma=\frac{\rho}{\Delta \rho}=\mathrm{f}_{4}\left(\frac{\mathrm{x}}{\mathrm{a}}, \gamma, \frac{\mathrm{L}_{\mathrm{R}}}{\mathrm{a}}, \frac{\mathrm{h}_{\circ}}{\mathrm{a}}, \frac{\mathrm{g}}{\mathrm{C}^{2}}, \frac{\mathrm{H}_{\circ}}{\mathrm{h}_{\circ}}, \frac{\mathrm{q}_{\mathrm{r}}}{\mathrm{h}_{\circ} \sqrt{\mathrm{gh}_{\circ}}}, \Gamma_{\circ}, \frac{\mathrm{L}}{\mathrm{a}}\right)
$$

At the limit of salinity intrusion, the salinity of water is approximately the same as the riverine water salinity and the above equation will become:

$$
\frac{\mathrm{L}^{\mathrm{HWS}}}{\mathrm{a}}=\mathrm{f}_{5}\left(\gamma, \frac{\mathrm{L}_{\mathrm{R}}}{\mathrm{a}}, \frac{\mathrm{h}_{\circ}}{\mathrm{a}}, \frac{\mathrm{g}}{\mathrm{C}^{2}}, \frac{\mathrm{H}_{\circ}}{\mathrm{h}_{\circ}}, \frac{\mathrm{q}_{\mathrm{r}}}{\mathrm{h}_{\circ} \sqrt{\mathrm{gh}}}, \frac{\Delta \rho}{\rho}, \frac{\mathrm{L}}{\mathrm{a}}\right)
$$

in which $\frac{\mathrm{L}^{\mathrm{HWS}}}{\mathrm{a}}$ is called the salinity intrusion number and the dimensionless parameters on the right-hand side of the equation are called the width ratio number, resonance number, estuary shape number, roughness number, tidal range number, riverine Froude number (Fr), density number and estuary length number, respectively. Savenije (1993) showed that the estuary shape number is a good indicator for shape of the intrusion curve and categorized estuaries using this parameter. He also used the tidal range number, i.e. tidal range to depth ratio, to characterize the salinity intrusion in the alluvial estuaries. In 
Eq. (29), the length of estuary is required for estimation of the width ratio number. Since the length of an estuary cannot be determined accurately, the width ratio number is not a proper dimensionless parameter in derivation of an empirical equation. Furthermore, according to Eq. (23), the riverine Froude number must be computed at the end of an estuary. Assuming constant riverine discharge and depth, the riverine Froude number at the end of the estuary is related to that of the estuary mouth. Therefore, the riverine Froude number is determined at the estuary mouth. In this way, the final form of the functional equation arrived from the scaling can be written as:

$$
\frac{L^{H W S}}{a}=f\left(\frac{L_{R}}{a}, \frac{h_{\circ}}{a}, \frac{g}{C^{2}}, \frac{H_{\circ}}{h_{\circ}}, F r, \frac{\Delta \rho_{\circ}}{\rho}\right)
$$

\section{Study area and the used model}

The Limpopo estuary was selected due to the availability of the extensive data from this estuary. The Limpopo River (Fig. 1) rises in Botswana and drains a large part of Transvaal in South Africa and the south-eastern part of Zimbabwe, some of the most developed economies in the region, and flows into the Indian Ocean at the city of Xai-Xai in Mozambique (Savenije 1992; UNEP 2005). In Mozambique, three main tributaries join the Limpopo River: the Nuanedzi River, the Changane River and the Elephants River (SARDC 2003). Limpopo is a single-branch estuary and its banks are regular which cross-channel variabilities along the estuary are ignorable. Bathymetry of Limpopo varies exponentially with distance from the mouth so that the water depth is constant along the entire estuary and the convergence lengths for both the cross-sectional area and the width are $50 \mathrm{~km}$ (Savenije 1993).

Numerical simulations were performed with a previously verified laterally averaged twodimensional model, named CE-QUAL-W2, as a virtual laboratory (see Parsa and Etemad-Shahidi 2009). This model has been widely used in modeling of estuaries and lakes (e.g. Kurup et al. 2000; Bown and Hieronymus 2003). The governing equations of the model are given in Cole and Wells (2009). 


\section{Results and discussion}

The calibrated and verified model in the previous work (Parsa and Etemad-Shahidi 2009) was used as a virtual laboratory to simulate the salinity intrusion in different conditions. In the calibration and verification of the model, several dispersion formulas, which were derived for estuaries and rivers, were tested for the tidally-averaged situation. As a result, the dispersion coefficient relationship of Savenije (2005) was used for the computation of the variation of the tidallyaveraged dispersion coefficient in different scenarios. The dispersion coefficient relationships for rivers were used where the Savenije's relationship could not be used for the computation of the dispersion coefficient due to the variation of each parameter. The model was executed for a number of different values of independent parameters. Based on the mentioned scaling, different values of riverine discharge, tidal range, mean water depth, roughness coefficient, salinity at the mouth, tidal period and convergence length were selected. In this way, seven sets of scenarios were considered in which salinity intrusion lengths were determined in all of them. In what follows, influences of the effective parameters on the salinity intrusion length are described in both dimensional and dimensionless forms.

\subsection{Dimensional parameters}

First, the influence of the effective dimensional parameters is described. The regression analysis between the salinity intrusion length and each dimensional parameter showed that the logarithmic function can be used to explain the governing relationships. This is in agreement with the analytical solution of the advection-diffusion equation in the alluvial estuaries which results in a logarithmic function. Since the relationships reported in the most of previous studies were in the form of power function (e.g. Rigter 1973; Monismith et al 2002), the obtained relationships, here, were presented in the power form and were compared with previously published results.

\subsubsection{Effect of riverine discharge}

As riverine discharge increases, the salinity field is pushed downstream toward the mouth (Savenije 2005). The response of the salinity intrusion length to varying riverine discharge was studied for river flow rates ranging from $Q=1 \mathrm{~m}^{3} / \mathrm{s}$ to $\mathrm{Q}=20 \mathrm{~m}^{3} / \mathrm{s}$. Figure $2 \mathrm{a}$ shows the salinity intrusion lengths versus the riverine discharges. This relationship can be presented in the form of a 
power function as $\mathrm{L}^{\mathrm{HWS}} \sim \mathrm{Q}^{-0.26}$ with $\mathrm{R}^{2}=0.961$. This finding is supported by previous studies. Oey (1984) carried out a theoretical investigation on the salinity intrusion in unstratified estuaries. His measurements in Hudson estuary indicated that $\mathrm{L}^{\mathrm{HWS}} \sim \mathrm{Q}^{-0.2}$. Theoretical arguments of Monismith et al. (2002) also showed that $\mathrm{L}^{\mathrm{HWS}} \sim \mathrm{Q}^{-0.33}$ while the field measurements in San Francisco bay showed that the salinity intrusion length is correlated with $\mathrm{Q}^{-0.14}$. The theoretical arguments of Monismith et al. (2002) are based on the work of Hansen and Rattray (1965) in which they used constant bathymetry. The analysis of Ralston et al. (2008) indicated that the lower sensitivity of the salinity intrusion in San Francisco Bay to the discharge variation is mainly due to the along-channel bathymetry. Zahed et al. (2008) carried out a numerical study on Arvand estuary and showed that $\mathrm{L}^{\mathrm{HWS}} \sim \mathrm{Q}^{-0.2}$. Becker et al. (2010) studied the effect of riverine discharge on the salinity intrusion length in the Cape Fear River estuary using a power-law regression analysis. Their analysis indicated that this relationship can be approximated by $\mathrm{L}^{\mathrm{HWS}} \sim \mathrm{Q}^{-0.2}$. The importance of variation of channel bathymetry has been also echoed by other investigators (e.g. Gay and O’Donnell 2007; Etemad-Shahidi et al. 2011). It seems that the difference between the values of the exponents may be related to variations in bathymetry and width along the estuaries.

\subsubsection{Effect of tidal range}

The tide drives the flow which causes different mixing mechanisms in estuaries. The resultant mixing in an estuary, originates from shear mixing, tidal trapping, gravitational circulation and tidal pumping. The shear mixing is not the important mixing mechanism in estuaries (Savenije 2005). Tidal trapping is the result of the irregularity of the estuary banks which is not the case (Savenije 2005). The key mixing mechanisms in the studied estuary are gravitational circulation and tidal pumping. A higher tidal range results in stronger tidal currents as well as enhanced horizontal mixing (Fischer et al. 1979).

The model was also executed for different values of tidal ranges. As expected, the salinity moves further upstream as the tidal range increases. Figure $2 \mathrm{~b}$ indicates that the relationship between the salinity intrusion length and tidal range can be demonstrated by $\mathrm{L}^{\mathrm{HWS}} \sim \mathrm{H}_{\circ}^{0.45}$ with $\mathrm{R}^{2}=0.984$. The amplitude of tidal velocity can be considered as a linear function of tidal range (Ippen 1966; Prandle 2004). Hence, all foregoing empirical models have indicated that the salinity intrusion 
length in LWS and TA are directly related to tidal range. Rigter (1973), Fischer (1974) and Van Os and Abraham (1990) models show that $\mathrm{L}^{\mathrm{LWS}} \sim\left(\mathrm{H}_{\circ}^{0.25}-\mathrm{H}_{\circ}^{1}\right)$ and Van der Burgh (1972) model shows that $\mathrm{L}^{\mathrm{TA}} \sim \mathrm{H}_{\circ}^{0.5}$. These findings imply that the obtained power function describes well the effect of tidal range on the salinity intrusion length. The obtained relationship also indicates that the salinity intrusion length is very sensitive to tidal range variations.

\subsubsection{Effect of water depth}

As the depth increases, the tidal velocity decreases while the resultant tidal discharge would increase because of the increase in cross-sectional area. The effect of varying water depth was examined with simulations using water depths ranging from $4 \mathrm{~m}$ to $9 \mathrm{~m}$. The simulated salinity intrusion lengths are displayed in Figure 2c against the water depths. As indicated in this figure, $\mathrm{L}^{\mathrm{HWS}} \sim \mathrm{h}_{\circ}^{0.61}$ with $\mathrm{R}^{2}=0.939$.

\subsubsection{Effect of roughness coefficient}

In an estuary, the increase of energy due to the entering tide is dissipated by friction (Savenije 2005). The effect of varying roughness coefficient on the salinity intrusion was considered using the different values of Chezy coefficient. Salinity intrusion length varies slightly with the roughness variations. As shown in Figure 2 d, the salinity intrusion length can be stated by $\mathrm{L}^{\mathrm{HWS}} \sim$ $C^{0.15}$. The low value of the exponent of Chezy coefficient in this relationship and the limited range of Chezy coefficient variation in estuaries imply that the roughness coefficient is not a key parameter for salinity intrusion length.

\subsubsection{Effect of density difference}

The horizontal salinity gradient resulting from the input of freshwater from the river and saltwater from the mouth induces a horizontal density gradient that drives an imbalance in hydrostatic pressure which causes gravitational mixing (Savenije 2005; Becker et al. 2010). The other set of simulations was carried out to examine the influence of density difference on the salinity intrusion. The results showed that the increasing of density difference between the riverine water and seawater causes more intrusion of salinity in the upstream direction of an estuary. Figure 2e 
indicates that the direct relationship between salinity intrusion length and density difference can be well demonstrated by $L^{H W S} \sim \Delta \rho_{\circ}^{0.34}$. This relationship is comparable with that of Oey (1984) where correlation of salinity intrusion length with salinity difference for Hudson estuary indicated that $L^{\text {HWS }} \sim \Delta S_{\circ}^{0.35}$. Hamrick (1979) carried out a series of laboratory experiments in which $\Delta \mathrm{S}_{\text {。 }}$ was varied while the other flow variables kept constant. Oey (1984) examined these data and

found that $L^{\mathrm{HWS}} \sim\left(\Delta \mathrm{S}_{\circ}^{0.3}-\Delta \mathrm{S}_{\circ}^{0.7}\right)$. Considering the equation between density and salinity of water (i.e. $\rho=\rho_{\circ}+0.75 \mathrm{~S}$ ), the obtained relationship is well supported by these findings.

Although this relationship implies that density difference is an important parameter in the salinity intrusion, it should be noted that the values of seawater salinities are usually in a limited range from 25 to 35 ppt. Therefore, this variable does not vary much and cannot be considered as a key parameter.

\subsubsection{Effect of tidal period}

The response of the salinity intrusion length to different tidal periods was also examined. As shown in Figure 2f, the salinity intrusion length has a direct relationship with tidal period. This relationship can be presented in the form of a power function as $\mathrm{L}^{\mathrm{HWS}} \sim \mathrm{T}^{0.17}$ with $\mathrm{R}^{2}=0.825$. This is in-line with the findings of Rigter (1973) which showed that the salinity intrusion length is directly related to the tidal period.

\subsubsection{Effect of convergence length}

The interaction between the topography and main mixing driven factors, especially tide and riverine discharge, determines the salinity distribution along an estuary (Dyer 1997; Savenije 2005). To better understand the salinity intrusion phenomenon in the alluvial estuaries, it is also necessary to examine the effects of the along channel convergence. Hence, the model was executed for different convergences ranging from 40 to $150 \mathrm{~km}$. Figure $2 \mathrm{~g}$ shows that the salinity intrusion length can be well given by $\mathrm{L}^{\mathrm{HWS}} \sim \mathrm{a}^{0.44}$ with $\mathrm{R}^{2}=0.976$. This result implies that the convergence is a very important parameter in the salinity intrusion phenomenon. 
It could be argued that the obtained results can be somewhat altered by choosing another base case or another range of data for some parameters such as the riverine discharge. However, the dimensionless parameters are considered to overcome these weaknesses.

\subsection{Dimensionless parameters}

Here, influences of the dimensionless parameters on the salinity intrusion length are described. Attempt is made to find a simple dimensionless mathematical function, based on the analytical solution of advection-diffusion equation in the alluvial estuaries, for the salinity intrusion length (Eq. (5)).

\subsubsection{Effect of resonance number}

Variations of the tidal period cause changes in the resonance number. The influence of the resonance number is plotted versus the salinity intrusion number in Figure 3a, indicating that $\frac{\mathrm{L}^{\mathrm{HWS}}}{\mathrm{a}}=\ln \left[1+1.312\left(\frac{\mathrm{L}_{\mathrm{R}}}{\mathrm{a}}\right)^{0.991}\right]$. It is seen that the salinity intrusion number is directly related to the resonance number which is in agreement with the findings of Rigter (1973).

\subsubsection{Effect of estuary shape number}

The effects of the water depth and convergence length are considered to evaluate the influence of this dimensionless parameter on the salinity intrusion. To illustrate this relationship, the computed values of different estuary shape numbers are plotted against the salinity intrusion number. Figure $3 b$ indicates that the salinity intrusion number is a function of the estuary shape number as $\frac{\mathrm{L}^{\mathrm{HWS}}}{\mathrm{a}}=\ln \left[1+14139.47\left(\frac{\mathrm{h}_{\circ}}{\mathrm{a}}\right)^{0.975}\right]$. This coincides well with the work of Savenije (1993), which arrived at the equation in the same form. In that equation, the power of the estuary shape number is approximately 1 . Hence, the estuary shape number has a direct and considerable effect on the salinity intrusion number. 


\subsubsection{Effect of roughness number}

Only the third term on the right-hand side of Eq. (29) changes as the roughness coefficient changes. Plotting the different values of roughness number versus the salinity intrusion number (Figure 3c) indicates that the salinity intrusion length follows $\frac{\mathrm{L}^{\mathrm{HWS}}}{\mathrm{a}}=\ln \left[1+1.142\left(\frac{\mathrm{g}}{\mathrm{C}^{2}}\right)^{-0.127}\right]$, showing a weak dependency of salinity intrusion number on the roughness number.

\subsubsection{Effect of tidal range number}

To illustrate the effect of the tidal range number on the salinity intrusion number, it is necessary to plot the salinity intrusion numbers against different tidal ranges. Figure 3d shows the variations in the salinity intrusion number as a function of $\frac{H_{\circ}}{h_{\circ}}$. The results indicate that $\frac{\mathrm{L}^{\mathrm{HWS}}}{\mathrm{a}}=\ln \left[1+13.886\left(\frac{\mathrm{H}_{\circ}}{\mathrm{h}_{\circ}}\right)^{0.978}\right]$.

\subsubsection{Effect of riverine Froude number}

The response of salinity intrusion number to the riverine Froude number is displayed in Figure 3e. This figure shows that $\frac{\mathrm{L}^{\mathrm{HWS}}}{\mathrm{a}}=\ln \left[1+0.035(\mathrm{Fr})^{-0.482}\right]$. The previously mentioned empirical models make clear that the salinity intrusion is inversely related to the riverine Froude number. Rigter (1973) and Van Os and Abraham (1990) models state that $\mathrm{L}^{\mathrm{LWS}} \sim \mathrm{Fr}^{-1}$ while the Fischer (1974) model indicates that $\mathrm{L}^{\mathrm{LWS}} \sim \mathrm{Fr}^{-0.25}$. The model of Van der Burgh (1972) shows that $\mathrm{L}^{\mathrm{TA}} \sim \mathrm{Fr}^{-0.5}$. On the other hand, the obtained result coincides well with the Savenije (1993) work. In the Savenije (1993) model, the salinity intrusion number is related to the logarithm of $\mathrm{Fr}^{-0.5}$. As a result, the riverine Froude number has an inverse effect on the salinity intrusion length.

\subsubsection{Effect of density number}

Figure $3 f$ displays the effect of relative density difference on the salinity intrusion number. The relationship between these dimensionless parameters corresponds to 
$\frac{\mathrm{L}^{\mathrm{HWS}}}{\mathrm{a}}=\ln \left[1+18.747\left(\frac{\Delta \rho_{\circ}}{\rho}\right)^{0.57}\right]$. Since the convergence length was constant in these scenarios, the relationship is closely comparable to that of Oey (1984).

In brief, the results indicate that high correlations can be found between these dimensionless parameters and the salinity intrusion number. The regression analysis between the dimensionless parameters on the right-hand side of Eq. (30) and salinity intrusion number shows that the following logarithmic function fits well to the results:

$$
\frac{\mathrm{L}^{\mathrm{HWS}}}{\mathrm{a}}=130.3 \ln \left[1+\left(\frac{\mathrm{L}_{\mathrm{R}}}{\mathrm{a}}\right)^{0.14}\left(\frac{\mathrm{h}_{\circ}}{\mathrm{a}}\right)^{0.63}\left(\frac{\mathrm{g}}{\mathrm{C}^{2}}\right)^{-0.08}\left(\frac{\mathrm{H}_{\circ}}{\mathrm{h}_{\circ}}\right)^{0.41} \mathrm{Fr}^{-0.31}\left(\frac{\Delta \rho_{\circ}}{\rho}\right)^{0.43}\right]
$$

with $\mathrm{R}^{2}=0.976$. The high correlation indicates that the used scaling to derive the dimensionless parameters was successful.

The comparison of Eq. (31) with the previous empirical models indicates an important advantage of this equation. It uses directly the tidal range while all the previous models use the amplitude of tidal velocity. Since the accurate estimation of tidal velocity amplitude is more difficult, this is an important advantage for Eq. (31). Hence, this equation can be used successfully as a simple tool for the prediction of the salinity intrusion length in the alluvial estuaries in which the unstratified condition is met and the convergence lengths for cross-sectional area and width are the same.

\section{Summary and Conclusion}

In the present work a comprehensive study has been carried out on the salinity in alluvial estuaries. As an important part of this study, the governing equations of the salinity intrusion length were first scaled to determine the effective dimensionless parameters. The scaling argument used in this study has the following advantages: (a) identifying the effective dimensional and dimensionless parameters in the salinity intrusion process, (b) considering the dimensionless parameters, which can overcome the weakness of choosing limited range of dimensional parameters, (c) considering the simultaneous and interactive effects of all parameters on the salinity intrusion using the derived functional relationship. Then, a previously verified model was utilized as a virtual laboratory to generate a more complete data set. Using regression analysis, the logarithmic function of Savenije 
(1993) is recognized as the best relationship between the effective dimensional/dimensionless parameters and the salinity intrusion in the entire data set. These relationships were compared with the results of the previous studies. The logarithmic function is also in agreement with the analytical solution of the advection- diffusion equation in the alluvial estuaries. In this way, a logarithmic function is presented for the prediction of the salinity intrusion length as a function of the effective dimensionless parameters. In addition, it is found that the length of the salinity intrusion is very sensitive to tidal range number whereas the least important parameters are roughness and resonance numbers. Unlike the previous empirical models, the proposed formula utilizes the tidal range, which is easier to estimate, instead of the tidal velocity amplitude. It is believed that this formula can be used to predict the effect of hydrological and geometrical variations in management of unstratified alluvial estuaries.

\section{Acknowledgement}

We greatly appreciate the discussions and constructive comments provided by Prof. H.H.G. Savenije and Dr. E. Jabbari on an early version of this manuscript. 


\section{References}

Attrill MJ (2002) A testable linear model for diversity trends in estuaries. J Animal Ecol 71(2): $262-269$

Becker ML, Luettich RA, Mallin MA (2010) Hydrodynamic behavior of the Cape Fear River and estuarine system: A synthesis and observational investigation of discharge-salinity intrusion relationships. Est Coast Shelf Sci 88:407-418.

Bown JD, Hieronymus JW (2003) A CE-QUAL-W2 model of Neuse Estuary for total maximum daily load development. J Wat Res Plan Manag 129(4):283-294.

Cole TM, Wells SA (2009) CE-QUAL-W2: A two dimensional, laterally averaged hydrodynamic and water quality model. Version 3.6, User Manual, Prepared for U.S Army Corps of Engineers Waterway Experiment Station, 681pp.

Dyer KR (1997) Estuaries: a physical introduction. 2nd edn. John Wiley and Sons.

Etemad-Shahidi A, Dorostkar A, Liu WC (2008) Prediction of salinity intrusion in Danshuei estuarine system. Hydrol Res 39(5-6):497-505.

Etemad-Shahidi A, Parsa J, Hajiani M (2011) Salinity intrusion length: comparison of different approaches. Proc Instit Civil Engrs Maritime Engineering 164:33-42.

Etemad-Shahidi A, Imberger J (2002) Anatomy of turbulence in a narrow and weakly stratified estuary. J Mar Fresh Res 53(4):757-768.

Fischer HB (1974) Discussion of 'Minimum length of salt Intrusion in estuaries' by BP Rigter 1973. J Hydr Div Proc ASCE 100:708-712.

Fischer HB, List EJ, Imberger J, Koh CY and Brooks NH (1979) Mixing in Inland and Coastal Waters. Academic Press, San Diego,CA, USA.

Gay PS, O’Donnell J (2007) A simple advection-dispersion model for the salt distribution in linearly tapered estuaries. J Geophys Res 112:1-12, C07021. doi:10.1029/2006JC003840.

Graas S, Savenije HHG (2008) Salt intrusion in the Pungue estuary, Mozambique: effect of sand banks as a natural temporary salt intrusion barrier. Hydrol. Earth Sys Sci Disc 5:2523-2542.

Hamrick JM (1979) Salinity intrusion and gravitational circulation in partially stratified estuaries. $\mathrm{PhD}$ thesis, University of California, Berkeley, $451 \mathrm{pp}$. 
Hansen DV, Rattray M (1965) Gravitational circulation in straits and estuaries. J Mar Res 23:104122.

Hetland R, Geyer W (2004) An idealized study of the structure of long partially mixed estuaries. J Phys Oceanogr 34:2677-2691.

Ippen AT (1966) Estuary and coastline hydrodynamics. McGraw-Hill, New York, USA.

Jassby A, Kimmerer W, Monismith S, Armor C, Cloern J, Powell T, Schubel J, Vendlinski T (1995) Isohaline position as a habitat indicator for estuarine populations. Ecol Appl 5:272-289.

Kapsimalis V, Masse L, Tastet JP (2004) Tidal impact on modern sedimentary facies in the Gironde estuary, Southwestern France. J Coast Res, Special Issue 41:1-11.

Kurup RG, Hamilton DH, Phillips RL (2000) Comparison of two 2-dimensional, laterally averaged hydrodynamic model applications to the Swan River Estuary. Math Comp in Simul 51:627-638.

Liu WC, Chen WB, Wu CH (2008) Modeling effects of realignment of Keelung River, Taiwan. Proceedings of the ICE-Maritime Engrg 161(2):73-87.

Monismith S, Kimmerer W, Burau J, Stacey M (2002) Structure and flow-induced variability of the subtidal salinity field in Northern San Francisco Bay. J Phys Oceanogr 32:3003-3019

Nguyen AD, Savenije HHG (2006) Salt intrusion in multi-channel estuaries: a case study in the Mekong Delta, Vietnam. Hydrol Earth Sys Sci 10:743-754.

Oey L (1984) On steady salinity distribution and circulation in partially mixed and well mixed estuaries. J Phys Oceanogr 14:629-645.

Parsa J, Etemad-Shahidi A, Hosseiny S, Yeganeh-Bakhtiar A (2007) Evaluation of computer and empirical models for prediction of salinity intrusion in the Bahmanshir estuary. J Coast Res, Special Issue 50:658-662.

Parsa J, Etemad-Shahidi A (2009) Prediction of the influence of estuarine modifications on the salinity intrusion. J Coast Res, Special Issue 56:1390-1394.

Prandle D (2004) Saline intrusion in partially mixed estuaries. Est Coast Shelf Sci 59:385-397.

Ralston DK, Geyer WR, Lerczak JA (2008) Subtidal salinity and velocity in the Hudson river estuary: observations and modeling. J Phys Oceanog 38(4):753-770.

Rigter BP (1973) Minimum length of salt intrusion in estuaries. J Hydr Div Proc ASCE 99:14751496. 
SARDC (2003) Limpopo river basin - Factsheet 1. SADC Water Sector. http://www.sardc.net/imercsa/Limpopo/pdf/Limpopo1.pdf. accessed 21 September 2006.

Savenije HHG (1986) A one-dimensional model for salinity intrusion in alluvial estuaries. J Hydrol 85:87-109.

Savenije HHG (1992) Rapid assessment technique for salt intrusion in alluvial estuaries. IHE Report. Series 27, Delft, Netherlands.

Savenije HHG (1993) Predictive model for salt intrusion in estuaries. J Hydrol, 148:203-218.

Savenije HHG (2005) Salinity and Tides in Alluvial Estuaries. Elsevier, Amsterdam.

Stamou AI, Memos CD, Kapetanaki ME (2007) Modeling water renewal in a coastal embayment. Proceedings of the ICE-Maritime Engrg., 160(3):93-104.

UNEP (2005) Atlantic and Indian Oceans Environment Outlook. United Nations Environment Programme, Nairobi, ISBN: 9280725254.

Van der Burgh P (1972) Ontwikkeling van een methods voor het voorspellen van ZoutverdeLingen in estuaria, Kanalen en Zeeen. Rijkswaterstaat Rapport, 10-72.

Zahed F, Etemad-Shahidi A, Jabbari E (2008) Modeling of salinity intrusion under different hydrological condition in Arvand River Estuary. Canadian J Civil Engrg 35:1476-1480.

Zhang E, Savenije HHG, Wu H, Kong Y, Zhu J (2011) Analytical solution for salt intrusion in the Yangtze Estuary, China. Est Coast Shelf Sci 91:492-501. 


\section{Figure captions}

Fig. 1 Limpopo estuary map and its main tributaries

Fig. 2 Correlations between the salinity intrusion length and the effective dimensional parameters, (a) riverine discharge, (b) tidal range, (c) water depth, (d) Chezy coefficient, (e) density difference, (f) tidal period and (e) convergence length

Fig. 3 Correlations between the salinity intrusion number and the effective dimensionless parameters, (a) resonance number, (b) estuary shape number, (c) roughness number, (d) tidal range number, (e) riverine Froude number and (f) density number 
Table 1. Existing empirical models for prediction of salinity intrusion length in estuaries.

\begin{tabular}{ccc}
\hline Reference & Formula & $\begin{array}{c}\text { Approach and major limitations } \\
\text { Rigter (1973) }\end{array}$ \\
\hline Fischer (1974) & $\mathrm{L}^{\mathrm{LWS}}=4.7 \frac{\mathrm{h}_{\circ}}{\mathrm{fWS}} \mathrm{F}_{\mathrm{d}}^{-1} \mathrm{~N}^{-1}$ & $\begin{array}{c}\text { constant geometry, using flume data } \\
\mathrm{f}\end{array}$ \\
Van der Burgh (1972) & $\mathrm{L}^{\mathrm{TA}}=24 \pi \frac{\mathrm{h}_{\circ}}{\mathrm{K}} \mathrm{F}_{\mathrm{d}}^{-0.75} \mathrm{~N}^{-0.25} \mathrm{~N}^{-0.5}$ & $\begin{array}{c}\text { constant geometry, using flume data } \\
\text { and scaling approach } \\
\text { analytical and scaling approaches }\end{array}$ \\
Van Os and Abraham (1990) & $\mathrm{L}^{\mathrm{LWS}}=4.4 \frac{\mathrm{h}_{\circ}}{\mathrm{f}} \mathrm{F}_{\mathrm{d}}^{-1} \mathrm{~N}^{-1}$ & $\begin{array}{c}\text { constant geometry, using flume data } \\
\text { and scaling approach }\end{array}$ \\
Savenije (1993) & $\mathrm{L}^{\mathrm{HWS}}=\mathrm{a} \ln \left(1+\frac{1}{\beta}\right)$ & $\begin{array}{c}\text { Exponentially varying geometry, using } \\
\text { field data, analytical and scaling } \\
\text { approaches }\end{array}$ \\
\hline
\end{tabular}




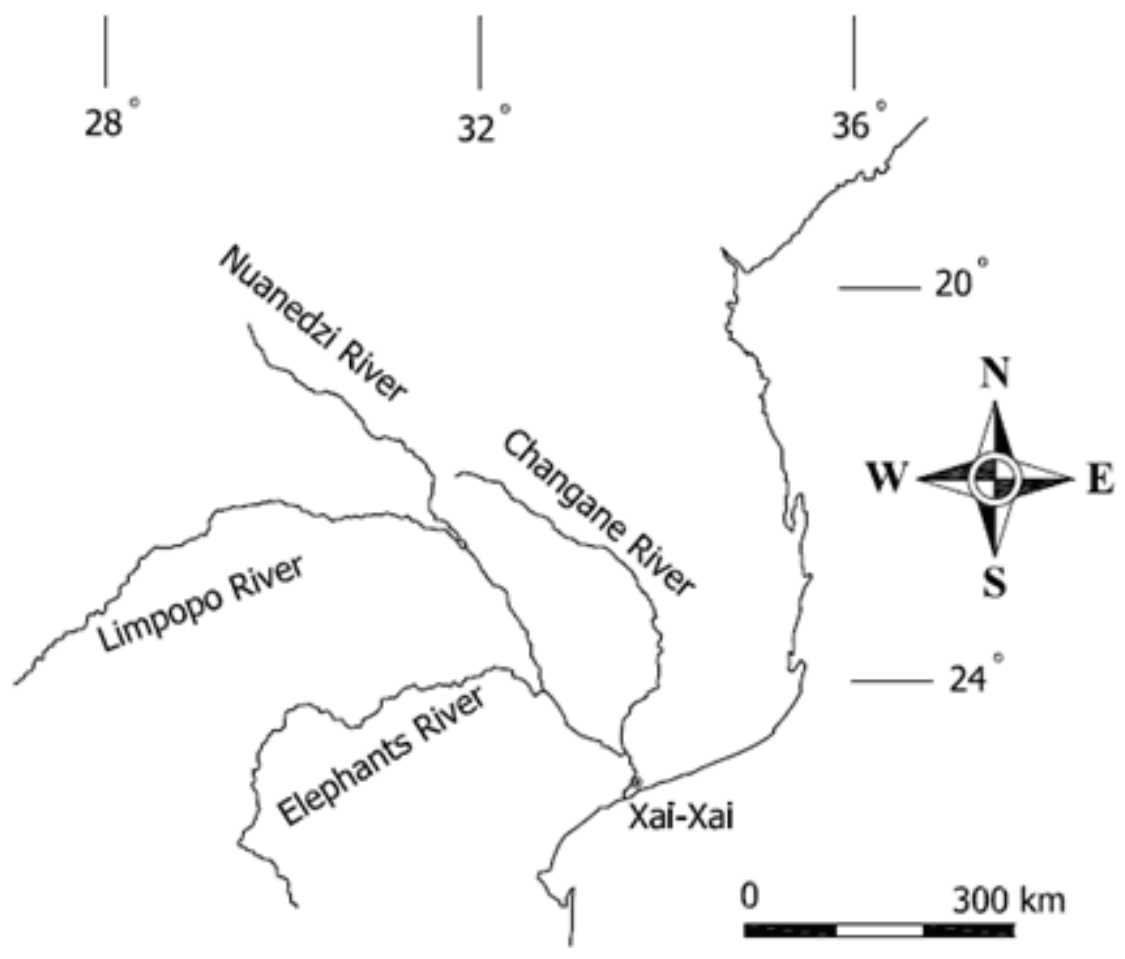

Fig. 1 Limpopo estuary map and its main tributaries 


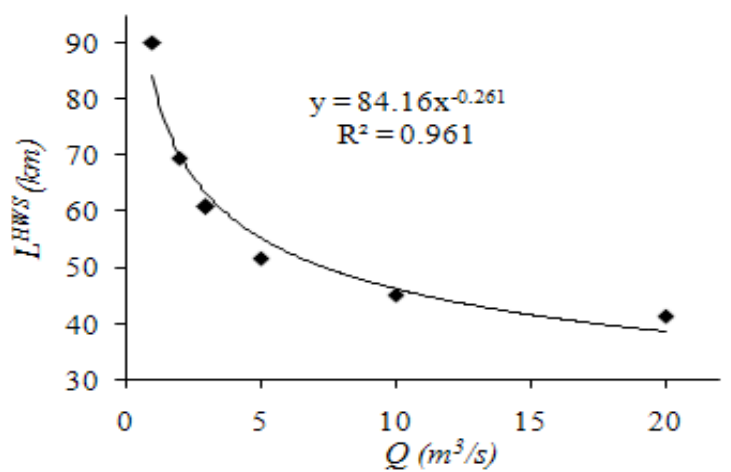

(a)

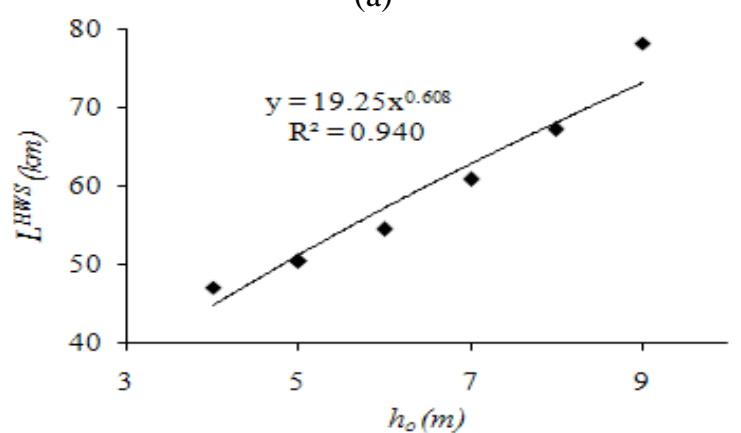

(c)

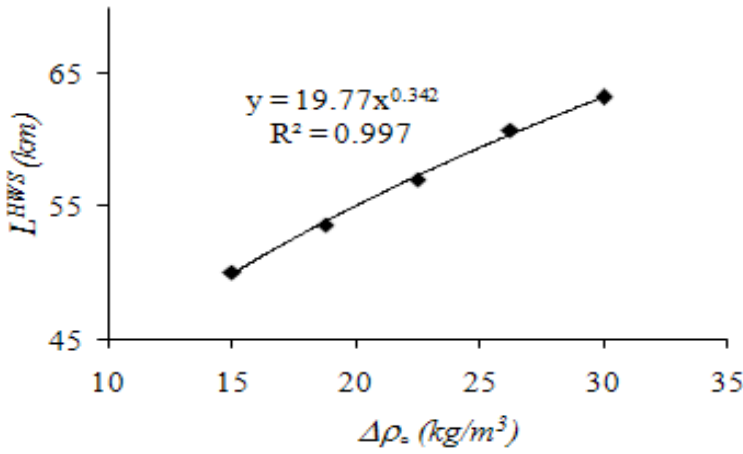

(e)

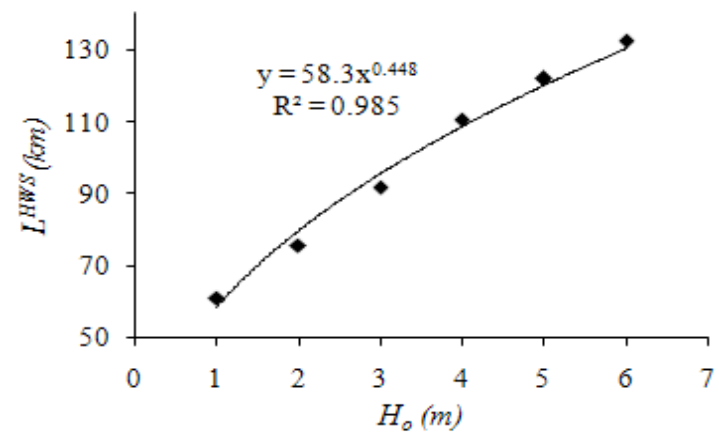

(b)

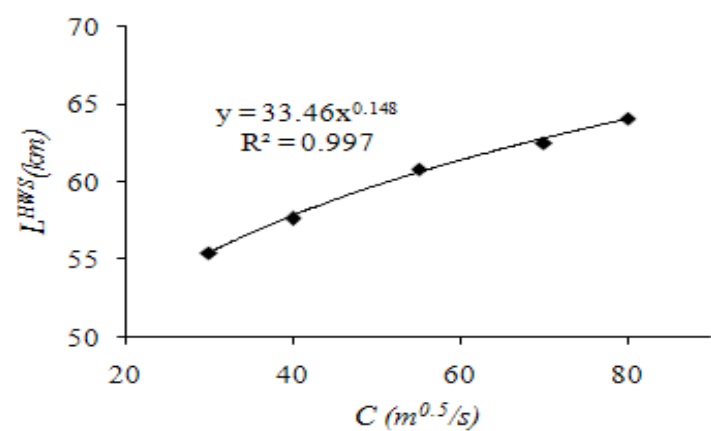

(d)

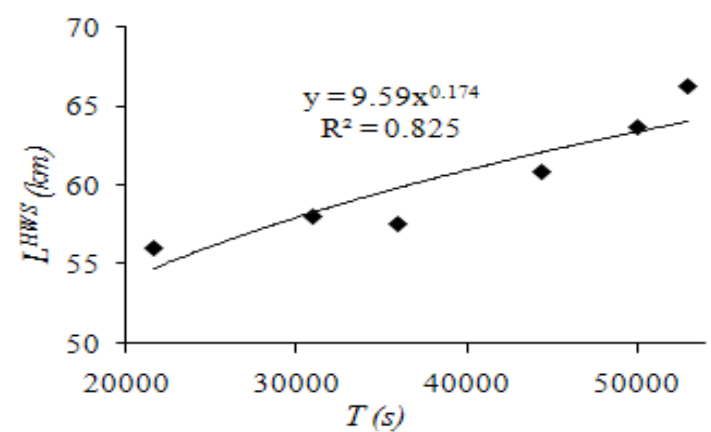

(f)

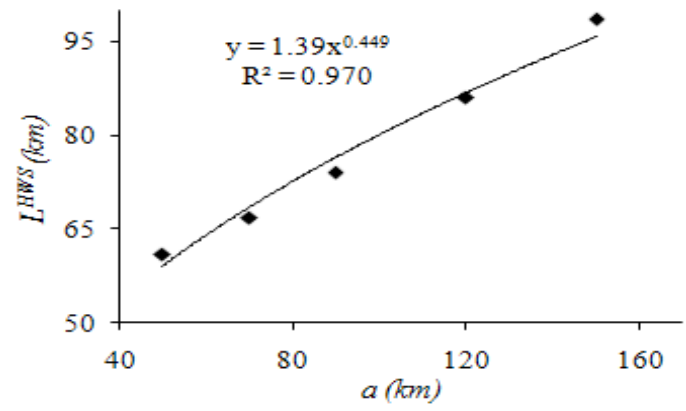

(g)

Fig. 2 Correlations between the salinity intrusion length and the effective dimensional parameters, (a) riverine discharge, (b) tidal range, (c) water depth, (d) Chezy coefficient, (e) density difference, (f) tidal period and (e) convergence length 


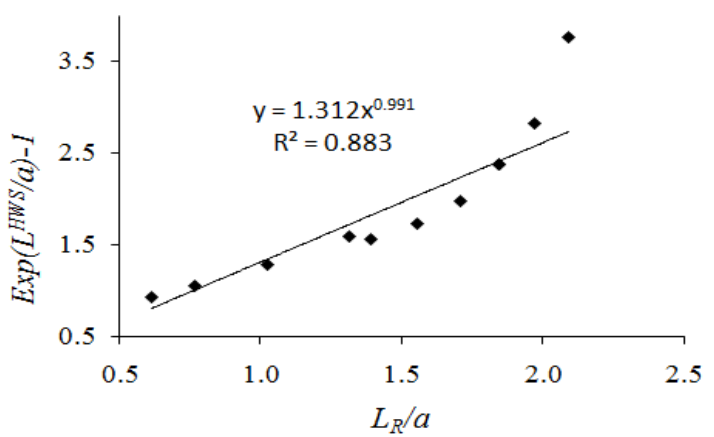

(a)

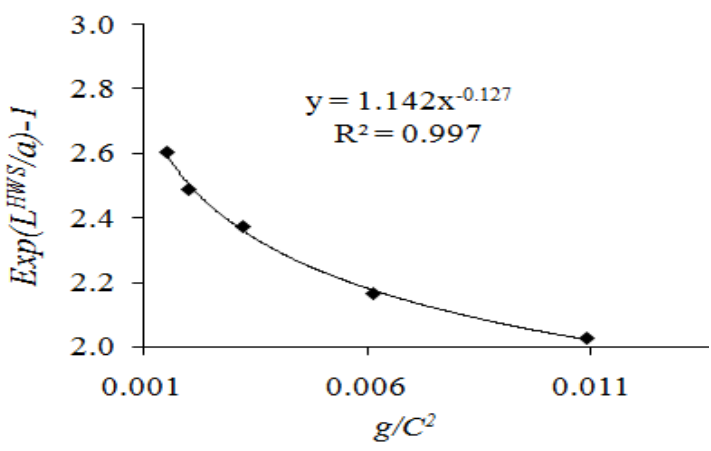

(c)

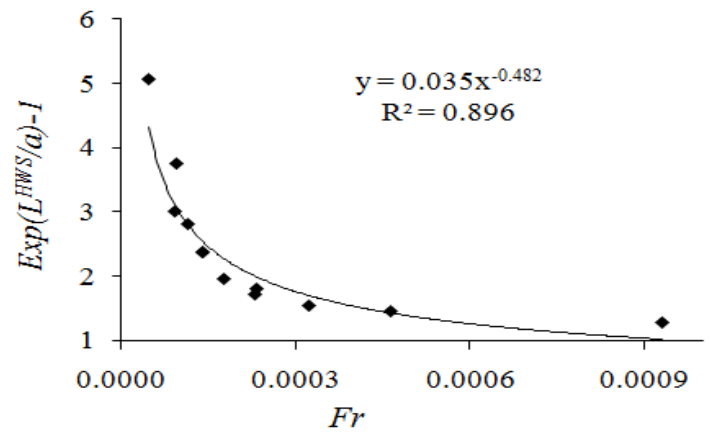

(e)

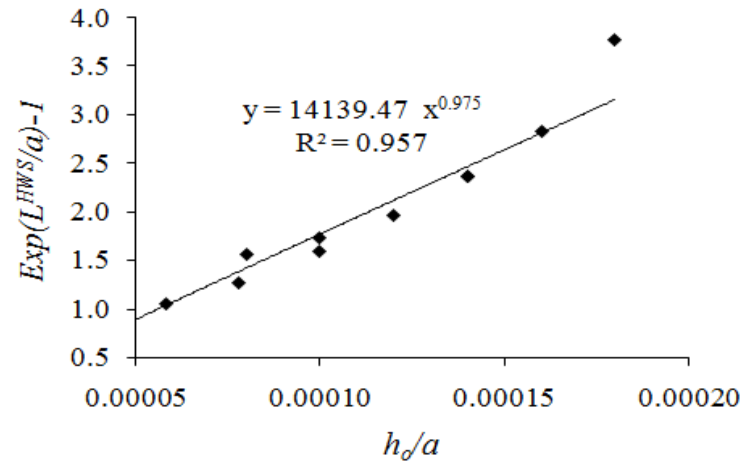

(b)

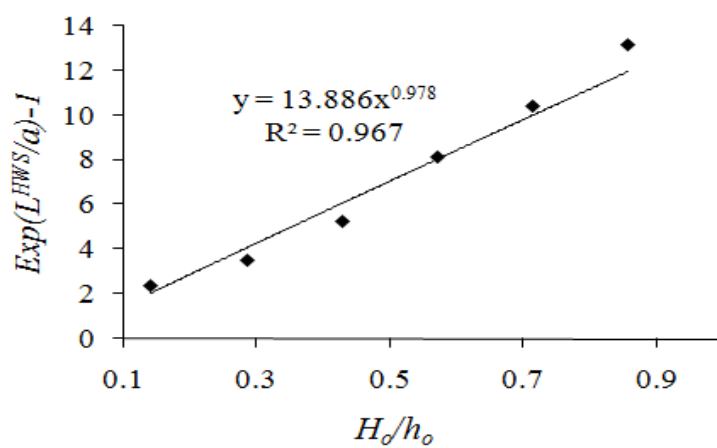

(d)

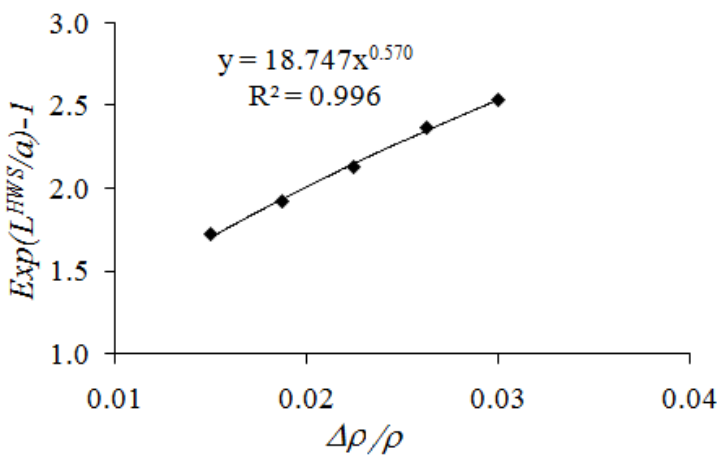

(f)

Fig. 3 Correlations between the salinity intrusion number and the effective dimensionless parameters, (a) resonance number, (b) estuary shape number, (c) roughness number, (d) tidal range number, (e) riverine Froude number and (f) density number 